\begin{tabular}{ccc}
\hline & International Journal of Engineering \&Technology, $7(3.12)(2018)$ 1086-1089 \\
SPC & Website www.sciencepubco.com/index.php/IJET \\
Research paper & Technology \\
\hline
\end{tabular}

\title{
Modeling and Analysis of Kaplan Turbine Blade Using CFD
}

\author{
K. Rama Chandra Manohar ${ }^{1 *}$, Somagani upendar ${ }^{2}$, V. Durgesh ${ }^{3}$, B.Sandeep ${ }^{4}$, \\ ksk mallik ${ }^{5}$, Gurram Narendra Santosh Kumar ${ }^{6}$, Sk.Hasane Ahammad ${ }^{7}$ \\ ${ }^{1}$ Research Scholar, Noida International University, Delhi \\ ${ }^{2}$ Assistant Professor, Anurag Group of Institutions, Hyderabad \\ ${ }^{3}$ Assistant Professor, Methodist College of engineering and technology, Hyderabad \\ ${ }^{4}$ D. V. R \& Dr. H.S MIC college of Technology, Kanchikacherla, Vijayawada \\ ${ }^{5,6}$ Department of Mechanical Engineering, Koneru Lakshmaiah Education Foundation, Vaddeswaram, A.P, India \\ *Corresponding Author Email: ${ }^{6}$ santoshnarendra1@ gmail.com
}

\begin{abstract}
Fluid assumes a basic part in huge numbers of the items that we experience each day from clear applications, for example, water treatment frameworks and auto and flying machine streamlined features to limit pushing. CFD investigation which empowers item outline and examination in a virtual domain has revolutionized liquid progression via robotizing the arrangement, notwithstanding for issues that are numerically substantial. By recognizing physical powers and stream attributes that are in some cases difficult to gauge or pick up knowledge into, CFD arrangements can help an organization drastically enhance time to showcase. Kaplan Turbine is Reaction, Axial and Adjustable Flow Turbine. In this Project displaying of Kaplan Turbine Will be finished by expecting shaft diam-eter, sprinter breadth and profile of the edge in Cero parametric Software. Computational Fluid Dynamic Analysis will have performed by im-porting the model in to CFD Software Ansys Fluent by expecting Initial Boundary Conditions (i.e. bay weight and Velocity. By Fixing Blade Twist point and differing flexible edge. Diverse CAD models will draw, and variety of stream parameters can be created along the turbine (i.e. weight and Velocity) in Ansys familiar Software. The above examinations to be performed for various Blade bend points. Suit-capable charts will be created between stream parameters. By this we will be in the situation to judge, which point is the most best one (the most best edge is the one which changes over the entire weight and speed of the liquid into valuable shaft work).
\end{abstract}

Keywords: Use about five key words or phrases in alphabetical order, Separated by Semicolon.

\section{Introduction}

A hydraulic powered machine is a gadget in which mechanical vitality is exchanged from the fluid moving through the machine to its working part (sprinter, cylinder and others) or from the working individual from the machine to the fluid coursing through it. Water driven machines in which, the working part gets vitality from the fluid moving through it and the bay vitality of the fluid is more noteworthy than the outlet vitality of the fluid are alluded as pressure driven turbines. Water driven machines in which vitality is transmitted from the working part to the streaming fluid and the vitality of the fluid at the outlet of the pressure driven machine is not as much as the outlet vitality are alluded to as pumps. It is outstanding from Newton's Law that to change energy of liquid, a power is required. Correspondingly, when energy of liquid is changed, a power is created. This standard is made use in water driven turbine. In a turbine, cutting edges or basins are given on a haggle against water to change the energy of water[1]. As the energy is changed with the water going through the wheel, the subsequent power turns the pole of the wheel performing work and creating power. A pressure driven turbine utilizes potential vitality and motor vitality of water and changes over it into usable mechanical vitality. vitality influenced accessible utilized to run an electric power generator which is straightforwardly which is acquired from the water driven vitality is known as Hydro-electric vitality. Water driven turbines have a place with the class of rotodynamic apparatus

\subsection{Classification of Hydraulic Turbines}

\section{i. According to the type of energy at inlet}

a. Impulse Turbine(IT)

In the IT, the aggregate leader of the approaching liquid is converted in to an extensive speed head at the exit of the supply nozzle. That is the whole accessible vitality of the water is changed over in to dynamic vitality. Even though there are different sorts of motivation turbine plans, maybe the most straightforward to comprehend is the Pelton wheel turbine. It is most proficient when worked with a vast head and lower stream rate.

\section{b. Response Turbine(RT)}

RTon the other hand, are most appropriate - for higher stream rate and lower head circumstances. In this kind of turbines, the turn of sprinter or rotor (pivoting some portion of the turbine) is somewhat because of motivation activity and mostly because of progress in weight over the sprinter cutting edges; along these lines, it is called as response turbine. For, a response turbine, the penstock pipe sustains water to a line of settled cutting edges through packaging. These settled edges change over a piece of the weight vitality into active vitality before water enters the sprinter. The water entering the sprinter of a response turbine has both 
weight vitality and dynamic energy.[2] Water leaving the turbine is still left with some vitality (weight vitality and active vitality) Since, the spill out of the delta to tail race is experiencing strain, packaging is completely important to encase the turbine. All in all, Reaction turbines are medium to low-head, and high-stream rate gadgets. The response turbines being used are Francis and Kaplan[3].

\section{ii. As indicated by the course of move through a Runner}

a. Tangential stream turbines: In this sort of tur-bines, the water strikes the sprinter toward digression to the wheel.

Illustration: Pelton wheel turbine.

b. Radial stream turbines: In this kind of turbines, the water strikes in the spiral course.

\section{iii. As needs be, it is additionally delegated}

a. Inward stream turbine: The stream is internal from pe-riphery to the middle (centripetal compose).

Illustration: old Francis turbine.

b. Outward stream turbine: The stream is outward from the inside to outskirts (divergent write).

\section{Case}

\section{Fourneyron turbine.}

c. Axial stream turbine: The stream of water is in the di-rection parallel to the hub of the pole.

\section{Case: Kaplan turbine and propeller turbine.}

d. Mixed stream turbine: The water enters the sprinter in the spiral bearing and leaves in hub heading.

\section{Case: Modern Francis turbine.}

\section{iv. As per the head at channel of turbine:}

a. High head turbine: In this sort of tur-bines, the net head shifts from $150 \mathrm{~m}$ to $2000 \mathrm{~m}$ or significantly more, and these turbines require a little amount of water.

Illustration: Pelton wheel turbine.

b. Medium head turbine: The net head shifts from $30 \mathrm{~m}$ to $150 \mathrm{~m}$, and furthermore these turbines require direct amount of water. Illustration: Francis turbine.

c. Low head turbine: The net head is under $30 \mathrm{~m}$ and these turbines require substantial amount of water.

Illustration: Kaplan turbine.

\section{Literature Review}

Tarun Singh Tanwar, et al. Fluid flow conditions and parameters within a Radial Turbine with regards to each part of the turbine in contact with the working fluid and all working parts of the Radial turbine Found that The maximum efficiency regime indicated by both approaches is nearly same. Reason for slight difference of efficiency computed by theoretically and CFD method can be because of human errors and due to discretisation of domains and solution of differential equations in computational methods.

Ketcheuzeu-Ngakam J, et al. Studied the Characterization of Hydrodynamics Parameters of a Kaplan Turbine by using Numerical analysis.. Found that the static pressure is too high near the volute walls and inside the distributors.

Mohamed Adel, et al. Studied the Numerical investigation of performance of kaplan turbine with draft tube. studied Kaplan turbine has a rotor with four blades mounted on a conical hub. The blade angle of the rotor is adjustable from $60^{\circ}$ to $80^{\circ}$. A computational liquid unique code was utilized (CFDRC, 2008) to demonstrate the temperamental two-stage stream field around the sharp edges of the Kaplan turbine.

\section{Kaplan Turbine (KT)}

$\mathrm{KT}$ is a propeller-type water turbine which has mobile edges. It was created in 1913 by Austrian instructor Viktor Kaplan, who joined automatically adjusted propeller bleeding edges with normally adjusted wicket ways to achieve profitability over a broad assortment of stream and water lev-el. Its creation allowed capable power age in low-head applications that was unreasonable with Francis turbines. The head ranges from 10- 70 meters and the yield from 5 to $200 \mathrm{MW}$. Sprinter removes crosswise over are some place in the scope of 2 and 11 meters.[4] Turbines turn at a reliable rate, which changes from office to office. That rate ranges from as low as69.2 rpm (Bonneville North Powerhouse, Washington U.S.) to $429 \mathrm{rpm}$. The Kaplan turbine foundation acknowledged to deliver the most power from its apparent head of $34.65 \mathrm{~m}$ is beginning at 2013 the Tacoma Power Plant (Venezuela) Kaplan turbine making $235 \mathrm{MW}$ with each one of ten $4.8 \mathrm{~m}$ width sprinters

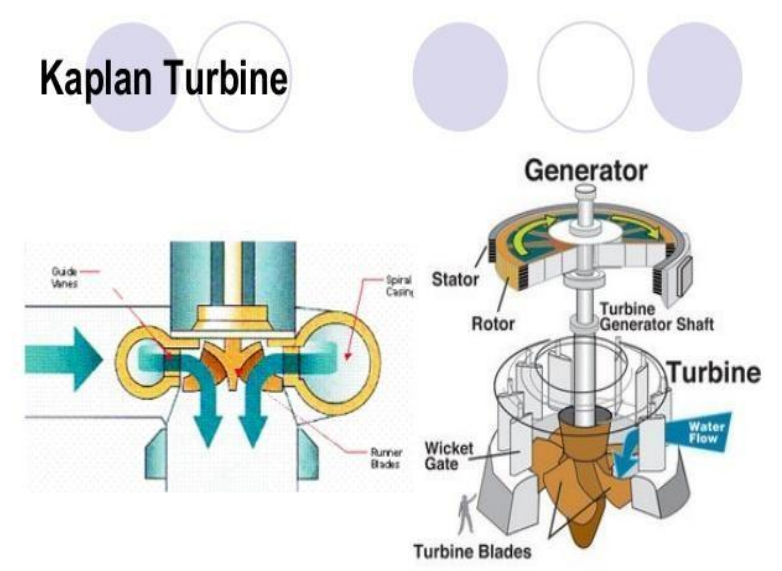

Fig. 1: Parts of Kaplan Turbine

\section{Theory of Operation}

$\mathrm{KT}$ is an outward stream reaction turbine, which suggests head and from the dynamic essentialness of the spilling water. The layout merges features of extended and center tur-bines [5]. The turbine does not ought to be and no more reduced motivation behind water stream if the draft tube remains stacked with water. A higher turbine territory, regardless, forms the suction that is offered on the turbine edges by the draft tube. The consequent weight drop may provoke capitation. over $90 \%$, yet may bring down in low head applications. Back and forth movement zones of research join CFD driven viability changes and new plans that raise survival rates of fish experiencing. Since the propeller edges are turned on high weight driven oil heading, a critical segment of Kaplan setup is to keep up a positive seal to prevent outpouring of oil into the waterway[6]. Arrival of oil into streams isn't attractive considering the abuse of benefits and occurring biological hurt.

\section{Turbine Blade Material}

Given that the turbine sharp edges in a water turbine are constantly presented to water and dynamic powers, they need high consumption obstruction and quality. The chromium content in these steel amalgams surpass the base of $12 \%$ chromium required to show some atmospheric erosion obstruction. More noteworthy weld-capacity takes into consideration easier repair of the turbine sharp edges. This likewise considers higher weld quality which brings about a superior repair. Choosing a material with low thickness is critical to accomplish higher proficiency claiming the lighter cutting edges turn more effectively. The most widely recognized material utilized as a part of Kaplan Turbine sharp edges are treated steel amalgams (SS)[7]. The diverse amalgams utilized 
are $\mathrm{SS}(16 \mathrm{Cr}-5 \mathrm{Ni}), \mathrm{SS}(13 \mathrm{Cr}-4 \mathrm{Ni}), \mathrm{SS}(13 \mathrm{Cr}-1 \mathrm{Ni})$. The martensitic tempered steel compounds have high quality, more slender areas than standard carbon steel, and lessened mass that upgrades the hydrodynamic stream conditions and effi-ciency of the water turbine. The SS(13Cr-4Ni) has been appeared to have enhanced disintegration obstruction at all approaches through the procedure of laser solidifying. It is critical to smaller than normal mize disintegration to keep up high efficiencies since disintegration negatively impacts the water driven profile of the edges which diminishes the relative straightforwardness to pivot.

\section{Design for Additive Manufacturing Printing)}

Streamline the Design Process for 3D Printing Using Additive Manufacturing (3D printing) for production parts can be like running an obstacle course. Once you move your product data through several different types of software, stopping to fix glitches along the way, you still have to contend with printer errors in all their rich variety. In the middle of this disconnected, stressful situation, it's only natural to ask yourself why someone can't make the 3D printing process easier. We agree with you. We call it 'Design for Additive Manufacturing'. We want you to get the most from Additive Manufacturing, a transformative technology for product designers, and experience 3D printing as a rewarding stroll rather than a punishing race removing uncertainty and rework from the process. The result? You now can go from concept to validation for 3D printing all within PTC CREO. When you use PTC CREO for additive manufacturing, you can printing* Save the CAD data, model translation, and position in the tray as one STL file Calculate the required amount of build and support materials[8].

\section{Modeling of Kaplan Turbine}

Modeling of our Kaplan turbine is carried out in creo-2 parametric software. At first, we design Kaplan turbine blade by using required commands, then after by using assembly part selection in creo-2 software we design shaft and we import blade and arrange them in required positions to get our assembly model.

\subsection{Design of Blade}

STEP-1: Blend, sections, Define, Plane selection sketch, sketch view. Draw bottom blade by using arc command.

STEP-2: Click on right mark, okay, sections, select blade length sketch, sketch view. Use center lines with required blade angle i.e. blade twist angle. Draw top blade profile by using arc command STEP-3: Select start point, click ok. Now you can see a 3-D blend model.

Use the round command for rounding the blade profile with required radius.

STEP-4: sketch, select base plane of blade, sketch view, circle extrude with require dimension, ok.

Then smooth the edges of base and blade profile

\subsection{Assembly}

Assembling of Kaplan turbine shaft and blades.

STEP-1: Select a plane, sketch, sketch view, circle with required dimension, ok

STEP-2: Extrude, Shaft length, ok.

By using assemble option we import the blade profile and attach in required position to the turbine shaft.

By selecting the coincident we match the blade profile base to the axis of the shaft perpendicularly and arrange them in perfect position.

By using the pattern command, we generate the three other blades to be arranged on the shaft at their required positions.
Thus, we obtain our required 3-D model of Kaplan turbine

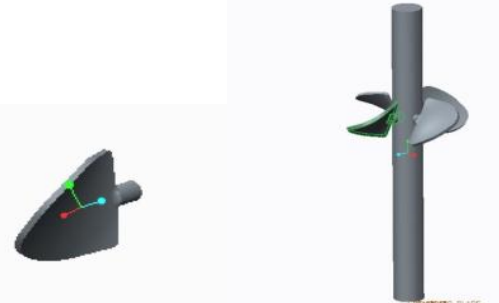

Fig. 2: Blade And Assembly View of Kaplan turbine.

\section{Computational Fluid Dynamic Analysis}

This analysis is performed in ansys fluent software. Analysis is carried by importing cad model from creo parametric and creating a control volume around the Kaplan turbine. The meshing is done in finite volume method i.e. ( the Flow path is divided into finite elements). By this the elements are set to be in continuum. Then we are giving the flow parameters i.e. selecting fluid as water, pressure and velocity at inlet by taking one side of enclosure. And this problem will be solved by taking number of iterations, finally pressure and velocity distribution along the flow path i.e. along the stream lines through the turbine, similar analysis will be performed to different turbines

Following parameters are related to the analysis pre-processor inputs have been considered for the analysis of turbine in dynamic conditions.

1. Taking fluid as a water

2. Pressure $=1$ bar.

3. Velocity $=35 \mathrm{~m} / \mathrm{s}$

\section{Results}

Now variation of parameters along the volume can be seen in the results. By following above procedure stimulation is done in ansys fluent where the fixed conditions are imposed at the entrance of the turbine. the velocity and pressure variations which are obtained by the following post-processing stage of ansys fluent. Similar type of analysis of performed in the different turbine models. Pressure and velocity variations can be found along the turbine in this analysis. In back ground the calculation is done by solving the second order degree differential equations of momentum and mass i.e. navier strokes equation. This variation can be found along the stream lines along the turbine. For plotting Results By Varying Adjustable angle and blade twist angle, the cad model are drawn. and CFD analysis is performed on them. Then results are plotted for pressure and velocity along the turbine. In the form of images as shown below. Different colour indicates the level of pressure and velocity of water. In that region. For velocity variations along the turbine are shown in the stream line path of the water so that it can be easily understood in what areas of the turbine stream lines getting closer i.e.so many water molecules are concentrated in that region. For pressure variation along the turbine are shown in the finite volume reading.

\section{For 15-15 turbine}

Pressure \& Velocity distribution:

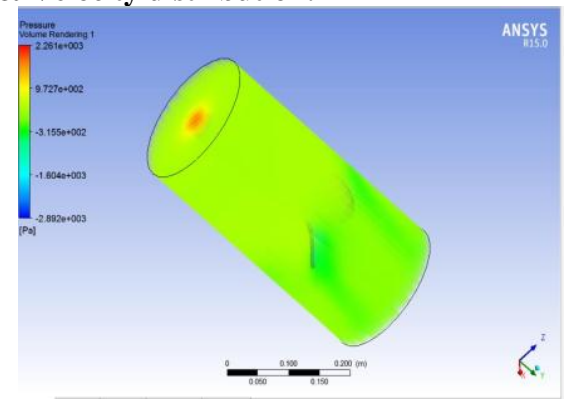




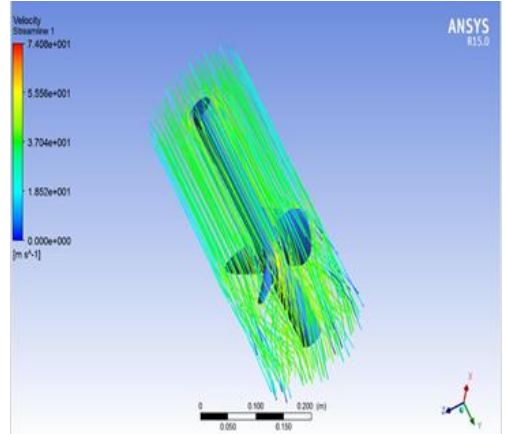

Fig. 3: Pressure and velocity distribution for 15-15 Turbine

\section{For 30-30 turbine}

\section{Pressure \& Velocity distribution:}
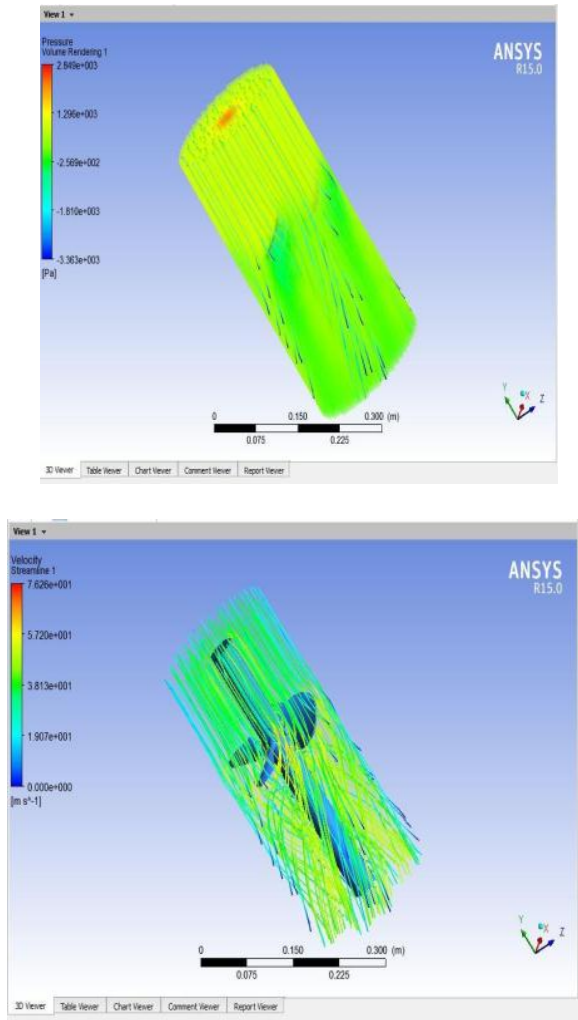

Fig. 4: Pressure and velocity distribution for 30-30 Turbine

\section{Conclusion}

In this Paper, by varying Blade Twist angles for different adjustment angles for Kaplan Turbines, Pressure and Velocity Distribution along the turbine is noted.
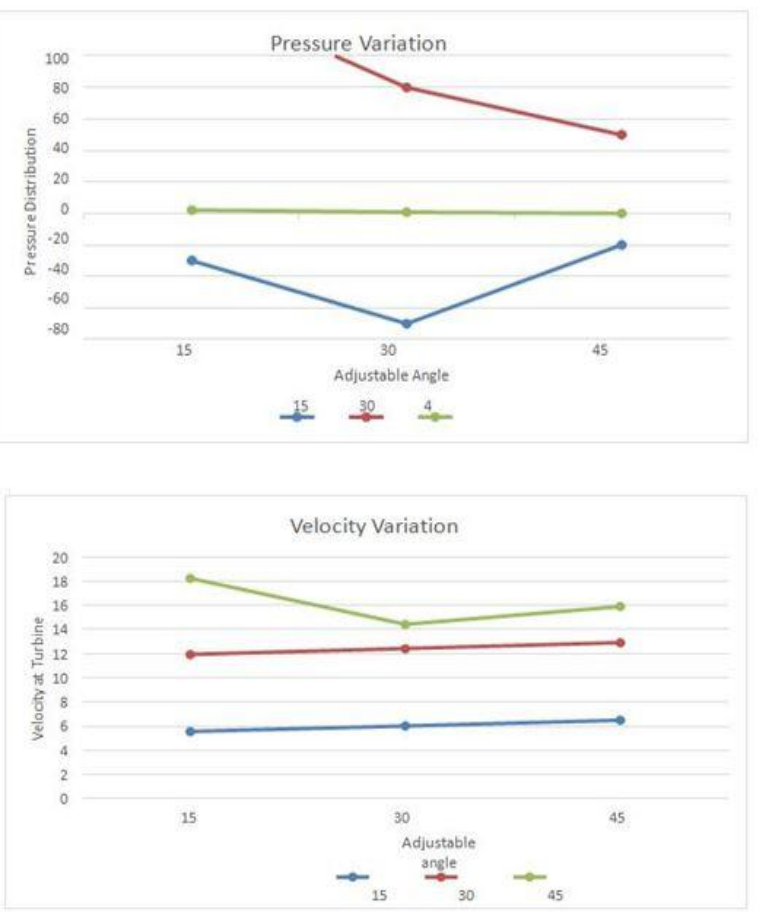

Fig. 5: pressure \& Velocity Variation

\section{References}

[1] Muhammad Abubakar., Saeed Badshah., "Modelling and Analysis of a very Low Head Kaplan Turbine Runner Blades for Rural Area of Punjab" International Journal of Scientific \& Engineering Research, Volume 5, Issue 7, July-2014 905 ISSN 2229-5518.

[2] Ajaz bashir janjua., muhammad shahid khalil., "Blade Profile Optimization of Kaplan Turbine Using CFD Analysis" Mehran University Research Journal of Engineering \& Technology, Volume 32, No. 4, October, 2013 [ISSN 0254-7821]

[3] Tarun Singh Tanwar., Dharmendra Hariyani., "flow simulation (cfd) \& static structural analysis (fea) of a radial turbine" international journal of mechanical engineering and technology (ijmet), Volume 3, Issue 3, September - December (2012), pp. 252-269.

[4] Ketcheuzeu-Ngakam J., Koueni-Toko C., "Characterization of Hydrodynamics Parameters of a Kaplan Turbine" Energy and Power 2014.

[5] Mohamed Adel., Nabil H. Mostafa., "Numerical investigation of performance of kaplan turbine with draft tube" Eighteenth International Water Technology Conference, IWTC18 Sharm elsheikh, 12 14 March 2015.

[6] Kumar, Gurram Narendra Santosh, and A. Srinath. "Exploration of Accelerating Moving Walkway for Futuristic Transport System in Congested and Traffical Areas." (2018): 616-624.

[7] Ajaz bashir janjua., muhammad saeed., "Blade Profile Optimization of Kaplan Turbine Using CFD Analysis". Mehran University Research Journal of Engineering \& Technology, 2013. Volume 32, No. 4: P. 559-574.

[8] Alok Mishra., M.K. Singhal., "CFD Based Performance Analysis of Kaplan Turbine for Micro Hydro Power", in International Conference on Mechanical and Industrial Engineering. 2011 